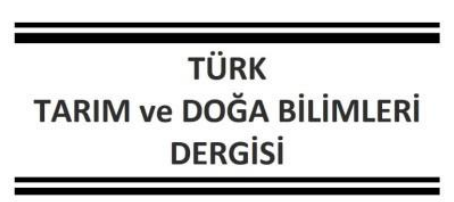

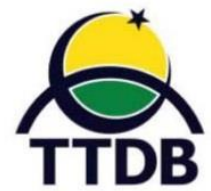

www.dergipark.gov.tr/turkjans

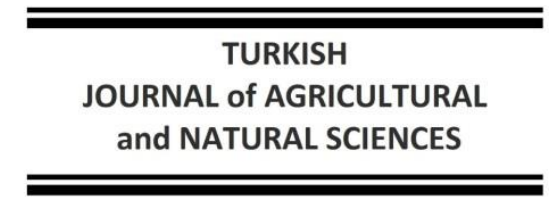

and NATURAL SCIENCES

\title{
Araştırma Makalesi \\ İç Anadolu Bölgesinde Bulunan Hayvansal Atıkların Biyogaz Potansiyelinin İncelenmesi
}

\author{
Gamze TOPAL CANBAZ ${ }^{1 *}$, Ayben POLAT BULUT ${ }^{2}$
}

${ }^{1}$ Sivas Cumhuriyet Üniversitesi, Mühendislik Fakültesi, Kimya Mühendisliği Bölümü, Sivas

${ }^{2}$ Sivas Cumhuriyet Üniversitesi, Mimarlık Güzel Sanatlar ve Tasarım Fakültesi, Şehir ve Bölge Planlama Bölümü, Sivas

*Sorumlu Yazar: gtopal@cumhuriyet.edu.tr

Geliş Tarihi: 30.11.2020 Düzeltme Geliş Tarihi: 20.08.2021 Kabul Tarihi: 12.10 .2021

\section{Öz}

Hızlı nüfus artışı, gelişen sanayi ve teknoloji ile enerji ihtiyacının artmasına neden olmuştur. Artan enerji talebinin karşılanması için fosil kaynakların kullanımının artması ile ilkim değişikliği, sera etkisi gözlenmesi ve ozon tabakasının zarar görmesi gibi çevresel sorunlar ortaya çıkmaktadır. Fosil kaynakların sınırlı olması ve kullanımı sonucunda ortaya çıkan zararları önlemek amacı ile çevre dostu yenilenebilir enerji kaynaklarının kullanımı gündeme gelmiştir. Çevre dostu ve yenilenebilir enerji kaynaklarından biri olan biyogaz enerjisi, organik atıklardan elde edilen biyogaz aynı zamanda bu atıkların bertarafı için de önem ve dikkat çekmektedir. Yapılan çalışmada, 2015 ve 2019 yılları için Türkiye İstatistik Kurumu'ndan (TÜiK) alınan veriler ile iç Anadolu Bölgesi biyogaz potansiyeli, biyogazdan elde edilecek olan enerji ve faydalanacak kişi sayısı hesaplanmıştır. Çalışmanın ilk aşamasında i̇ç Anadolu Bölgesi'nde bulunan tüm illerdeki büyükbaş hayvan (BBH), küçükbaş hayvan $(\mathrm{KBH})$ ve kanatlı hayvan $(\mathrm{KH})$ sayıları belirlenmiş, hayvanlardan elde edilen gübre ve enerji miktarları bulunmuştur. 2015 ve 2019 yılları için potansiyel enerji miktarı ve faydalanacak kişi sayısı sırası ile 3410 GWh ve 4275 GWh, 662657 ve 830773 olarak belirlenmiştir.

Anahtar kelimeler: Biyogaz, enerji, İç Anadolu Bölgesi, hayvansal atık

\section{Investigation of Biogas Potential of Animal Wastes in the Central Anatolia Region} \begin{abstract}
Rapid population growth, developing industry and technology has led to an increase in the need for energy. With the increase in the use of fossil resources to meet the increasing energy demand, environmental problems such as climate change, observation of the greenhouse effect and damage to the ozone layer arise. The use of environmentally friendly renewable energy sources has come to the fore in order to prevent the damages caused by the limited use of fossil resources. Biogas energy, which is one of the environmentally friendly and renewable energy sources, and biogas obtained from organic wastes also draw attention and importance for the disposal of these wastes.In the study, the biogas potential of the Central Anatolia Region, the energy to be obtained from biogas and the number of people who will benefit from it were calculated with the data obtained from the Turkish Statistical Institute (TUIK) for the years 2015 and 2019. In the first stage of the study, the numbers of bovine animals $(\mathrm{BBH})$, ovine animals $(\mathrm{KBH})$ and poultry $(\mathrm{KH})$ in all provinces in the Central Anatolia Region were determined, and the amounts of manure and energy obtained from animals were determined. The potential energy amount and the number of beneficiaries for the years 2015 and 2019 have been determined as $3410 \mathrm{GWh}$ and $4275 \mathrm{GWh}, 662657$ and 830773 , respectively.
\end{abstract}

Key words: Biogas, energy, Central Anatolia Region, animal waste

\section{Giriş}


Nüfusun artması, yeni teknolojilerin gelişmesi ve buna paralel olarak yükselen yaşam standardı kullanılan enerji miktarının da artmasına neden olmaktadır. Kullanılan enerji miktarındaki artış, enerji kaynaklarının tüketimini de arttırır ve artan tüketim ile talep edilen enerji miktarı karşılanamadığından enerji fiyatları da artar. Bu da her geçen gün daha pahalı enerji kullanımı ile sonuçlanmaktadır (Hammad ve ark. 1999). Ayrıca kömür, petrol ve doğalgaz gibi fosil kaynakların azalması ve işletme proseslerinden dolayı çevresel sorunların ortaya çıkması gibi problemlerle de karşılaşılmaktadır (Yasar ve ark. 2017). Yapılan çalışmalar; petrol rezervinin 2047, doğalgaz rezervinin 2068, kömür rezervinin ise 2140 yılına kadar tükeneceğini göstermektedir (Çağlayan, 2020). Bahsedilen sorunların önüne geçebilmek için yenilenebilir enerji kaynakları küresel enerji politikaları tarafından da desteklenerek önem kazanmaktadır. Biyogaz enerjisi çevre dostu ve diğer enerji kaynaklarına göre uygun maliyetli olması nedeni ile gün geçtikçe daha çok dikkat çekmektedir (Bulut ve Canbaz, 2019; Karim ve ark. 2005). Biyogazın, tarım ve hayvancılık sektöründen elde edilerek enerji ihtiyacının karşılanması gelişmiş ülkelerde uzun süredir uygulanan bir yöntemdir (Koçer ve Kurt, 2013).

Biyogazın gıda ve hayvansal atık kaynaklı oluşumu Şekil 1 'de verilmiştir. Biyogaz, organik yapılı maddelerin anaerobik (havasız ortam) parçalanması sonucu oluşan, renksiz, yanıcı ve ISı değeri yüksek olan bir yakıt türüdür (Kadam ve Panwar, 2017). Gıda ve hayvansal atıklardan biyogaz üretimi ile bu atıkların çevreye kontrolsüzce salınımının veya yakılarak kullanımı sonucunda ortaya çıkan atıkların çevreye salınımının da önüne geçilerek neden oldukları çevre kirliliği azaltılmaktadır.

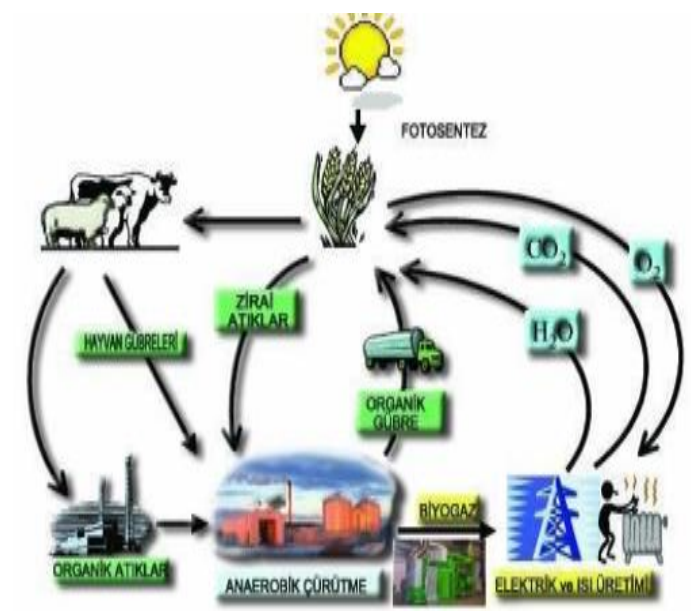

Şekil 1. Biyogaz oluşum çevrimi (Baran ve ark.. 2017).
Biyogazın ana bileşenlerini metan $\left(\mathrm{CH}_{4}\right)$ ve karbondioksit $\left(\mathrm{CO}_{2}\right)$ oluşturmaktadır. Bunların yanı

sıra su $\left(\mathrm{H}_{2} \mathrm{O}\right)$, hidrojen sülfür $\left(\mathrm{H}_{2} \mathrm{~S}\right)$, azot $\left(\mathrm{N}_{2}\right)$, hidrojen $\left(\mathrm{H}_{2}\right)$, oksijen $\left(\mathrm{O}_{2}\right)$, karbon monoksit $(\mathrm{CO})$ ve amonyak $\left(\mathrm{NH}_{3}\right)$ bulunmaktadır. Biyogazın bileşenleri ve yaklaşık \% hacimsel oranları Çizelge 1 ' de verilmiştir.

Çizelge 1. Biyogaz bileşimi (Deviren ve ark. 2017).

\begin{tabular}{l||l}
\hline Bileşen & Hacimsel \% \\
\hline Metan & $50-80$ \\
Karbondioksit & $20-50$ \\
Hidrojen sülfür & $0.0005-0.0002$ \\
Amonyak & $0.0005-0.0001$ \\
Azot & $0-3$ \\
Hidrojen & $0-5$ \\
Su & $0-1$ \\
\hline
\end{tabular}

Biyogaz üretimi tamamlandığında hayvan gübresinden kaynaklanan koku fark edilmeyecek kadar azalır ve gübre daha değerli bir hale gelerek organik gübreye dönüşür. Biyogaz tesisinde elde edilen ve sera gazları arasında bulunan metan gazı yakılma sonrasında $\mathrm{CO}_{2}^{\prime}$ e dönüşür. Biyogaz üretimi için gübreye uygulanan bu işlemler sayesinde, gübreden kaynaklanan insan ve çevre sağığını tehlikeye sokarak hastalıklara neden olan etmenlerin de etkisi kaybolarak daha temiz yaşam alanı sunar. Biyogazdan elektrik ve ISI üretimi ekonomik yönden de kazanç sağlar. Hayvancılığın gelişmesini teşvik ederek, suni gübre kullanımını ve dış ülkelere olan enerji bağımlılığını azaltarak ekonomiye katkıda bulunulmaktadır.

Bu çalışmada İç Anadolu Bölgesi' nde bulunan hayvansal atıklardan elde edilen biyogaz ve enerji üretim potansiyeli araştırılmıştır. Türkiye İstatistik Kurumu (TUIK) 2015 ve 2019 verilerinden yararlanarak her ildeki $\mathrm{BBH}, \mathrm{KBH}$ ve $\mathrm{KH}$ sayıları belirlenmiş ve i̇ç Anadolu Bölgesi toplam hayvan sayısı elde edilmiştir. 2015 ve 2019 yıllarındaki veriler ile biyogaz potansiyelindeki değişim değerlendirilmiştir.

\section{Materyal ve Metot}

İncelemenin yapıldığı İç Anadolu bölgesi Türkiye' de orta bölgede konumlanmış 7 coğrafi bölgeden biridir ve konumundan dolayı Orta Anadolu' da denmektedir. Bölgenin yüz ölçümü $151.000 \mathrm{~km}^{2 \prime}$ dir, ikinci büyük bölgedir ve Türkiye' nin \%21'ini oluşturmaktadır.

Yapılan çalışmada iç Anadolu bölgesinin biyogaz enerji potansiyelinin belirlenmesi amacı ile bölge içerisindeki illerin canlı hayvan sayıları ele alınmıştır. Illerdeki $\mathrm{BBH}, \mathrm{KBH}$ ve $\mathrm{KH}$ sayıları için 
Türkiye İstatistik Kurumu (TUIK) 2015 ve 2019 verilerinden faydalanılmış ve hesaplamalar yapılmıştır.

Bölgenin biyogaz potansiyelini belirlemek için aşağıdaki kabuller yapılarak sonuçlar değerlendirilmiştir.

- Gübre ile ilgili kabuller: Bir adet büyükbaş hayvandan 3.6 ton/yıl gübre, bir adet küçükbaş hayvandan 0.7 ton/yıl gübre, bir adet kanatlı hayvandan 0.022 ton/yıl gübre elde edildiği kabul edilir.

- Biyogaz ile ilgili kabuller: 1 ton büyükbaş hayvan gübresinden $33 \mathrm{~m}^{3}$ biyogaz, 1 ton küçükbaş hayvan gübresinden $58 \mathrm{~m}^{3}$ biyogaz, 1 ton kanatlı hayvan gübresinden $78 \mathrm{~m}^{3}$ biyogaz elde edildiği yapılan araştırmalar sonucu literatürde mevcuttur ve çalışmada bu değerler kullanılmıştır.

- Enerji ile ilgili kabuller: $1 \mathrm{~m}^{3}$ biyogazın sağladığı ısı miktarı; 3.47 kg oduna, 0.63 I gaz yağına, $0.43 \mathrm{~kg}$ bütan gazına, $4.7 \mathrm{kWh}$ elektriğe ve $0.8 \mathrm{~L}$ benzine eşdeğerdir (Altıkat ve Çelik, 2012).

- Enerjiden faydalanacak kişi sayısı ile ilgili kabuller: Bir kişinin günlük yemek pişirme ihtiyacı $0.35 \mathrm{~m}^{3}$ kişi gün ${ }^{-1}$ günlük 1 saat aydınlatma ihtiyacı için kullanım $0.15 \mathrm{~m}^{3}$ kişi gün ${ }^{-1}$ tüketim değerleri temel alınmış ve bir ailenin 5 kişiden oluştuğu varsayılarak hesaplamalar yapılmıştır (Çağlayan ve Koçer, 2014) .

\section{Bulgular ve Tartışma}

İç Anadolu bölgesinde bulunan 13 ile ait toplam BBH, KBH ve KH sayıları 2015 ve 2019 yılları için sırası ile 55612550 ve 55661609 olarak hesaplanmış ve oransal dağılımları Şekil 2' de verilmiştir. Toplam hayvan sayısında önemli bir fark gözlenmemiş fakat $\mathrm{BBH}, \mathrm{KBH}$ ve $\mathrm{KH}$ sayısındaki değişim 2015 ve 2019 yıllarındaki gübre, biyogaz ve enerji miktarını etkilemiştir.
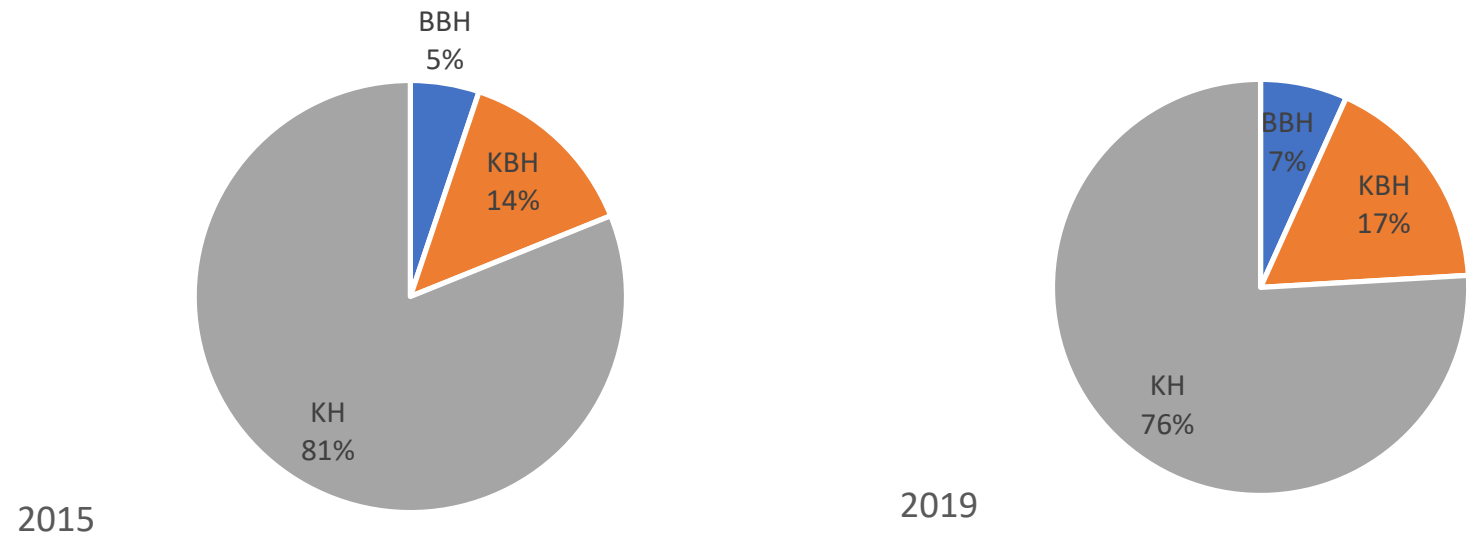

Şekil 2. İç Anadolu bölgesi 2015 ve 2019 yılı toplam BBH, KBH ve KH sayısının oransal dağılımı.

Çizelge 2' de bulunan il bazında hayvan sayısına bakıldığında en fazla hayvan 2015 yılında 16567167 hayvan ile Ankara' da, 2019 yılında ise 16606036 hayvan ile Konya' da olduğu belirlenmiştir. Çizelgeden yıl bazında toplam hayvan sayısı incelendiğinde ise 2015 yılından 2019 yılına BBH ve $\mathrm{KBH}$ sayısında artış olurken $\mathrm{KH}$ sayısında ise azalma olduğu görülmüştür.
Toplam BBH ve $\mathrm{KBH}$ sayısındaki artış, illerdeki nüfus artışı ile ilişkilendirilebilir. Şekil 3' te bulunan illere ve yıllara ait nüfus yoğunluğu değişim grafiği incelendiğinde çoğunlukla bütün illerde nüfus yoğunluğunda artış olduğu belirlenmiştir. 2015 ve 2019 yılları için İç Anadolu Bölgesinin toplam nüfusu ise sırası ile 12545317 ve 13283751 olarak belirlenmiştir. 
Çizelge 2. İç Anadolu bölgesi 2015-2019 yılları BBH, KBH ve KH sayıları (TÜIK).

\begin{tabular}{l||cc||cc||cc}
\hline \multirow{2}{*}{\multicolumn{1}{c||}{ iller }} & \multicolumn{3}{c||}{ BBH } & \multicolumn{2}{c||}{ KBH } & \multicolumn{2}{c}{ KH } \\
\cline { 2 - 7 } & $\mathbf{2 0 1 5}$ & $\mathbf{2 0 1 9}$ & $\mathbf{2 0 1 5}$ & $\mathbf{2 0 1 9}$ & $\mathbf{2 0 1 5}$ & $\mathbf{2 0 1 9}$ \\
\hline Aksaray & 181370 & 310549 & 513002 & $\mathbf{7 5 3 7 6 5}$ & 315121 & 319057 \\
\hline Ankara & 340112 & 549774 & 1062522 & 1746476 & 15164533 & 11443686 \\
\hline Çankırı & 128376 & 154860 & 122265 & 135983 & 3033324 & 2961354 \\
\hline Eskişehir & 128466 & 162855 & 808392 & 1034359 & 4333923 & 4286068 \\
\hline Karaman & 59206 & 71134 & 616976 & 676377 & 1138660 & 1120620 \\
\hline Kayseri & 293074 & 350237 & 638542 & 651505 & 3745266 & 4374950 \\
\hline Kırıkkale & 62423 & 77775 & 116258 & 145244 & 670607 & 306037 \\
\hline Kırşehir & 141614 & 236901 & 218897 & 286682 & 773658 & 877187 \\
\hline Konya & 740148 & 927082 & 2117190 & 2459960 & 13187101 & 13218994 \\
\hline Nevşehir & 74103 & 109635 & 120212 & 179081 & 825779 & 985067 \\
\hline Niğde & 147879 & 172019 & 546768 & 589828 & 833299 & 894638 \\
\hline Sivas & 365355 & $\mathbf{3 8 5 6 1 2}$ & 468690 & 636582 & 688161 & $\mathbf{7 7 2 1 5 4}$ \\
\hline Yozgat & 244350 & $\mathbf{2 4 5 8 2 5}$ & 407867 & 340094 & 1047705 & 663320 \\
\hline TOPLAM & $\mathbf{2 9 0 6 4 7 6}$ & $\mathbf{3 7 5 4 2 5 8}$ & $\mathbf{7 7 5 7 5 8 1}$ & $\mathbf{9 6 3 5 9 3 6}$ & $\mathbf{4 5 7 5 7 1 3 7}$ & $\mathbf{4 2 2 2 3 1 3 2}$ \\
\hline
\end{tabular}

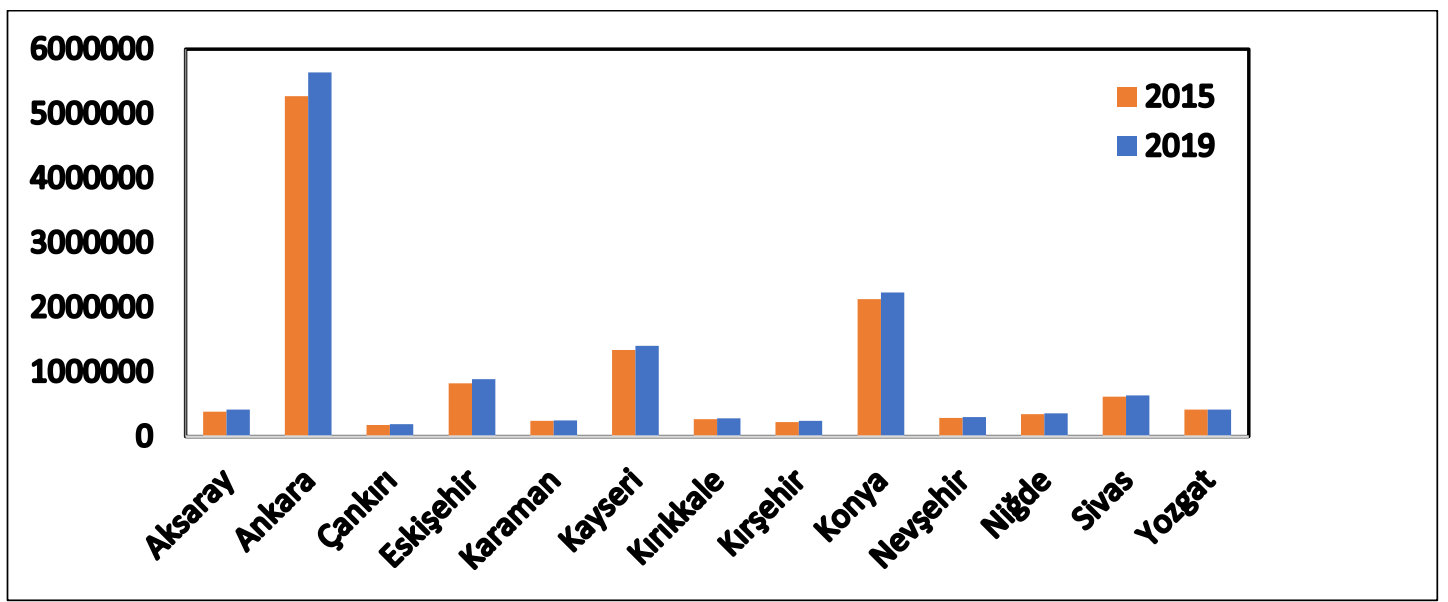

Şekil 3. illere göre nüfus dağılımı.

2015 ve 2019 yıllarında icç Anadolu illerine ait BBH, $\mathrm{KBH}$ ve $\mathrm{KH}$ sayısından elde edilen biyogaz üretim potansiyeli hesaplanarak Çizelge 3 ve Çizelge $4^{\prime}$ de sunulmuştur. 2015 ve 2019 yılları kıyaslandığında artan nüfus ve ortaya çıkan ihtiyaç ile birlikte hayvan sayısı da artmıştır. Bu artış çok fazla değildir fakat Şekil 3' de verilen oransal dağılım incelendiğinde $\mathrm{BBH}$ ve $\mathrm{KBH}$ sayısında artış, 2015 ve 2019 yılları kıyaslandığında gübre ve biyogaz miktarını etkilemiş fakat $\mathrm{KH}$ sayısındaki azalma, biyogaz miktarının artmasına engel olmamıştır.Çizelge 5 incelendiğinde iç Anadolu bölgesi içerisindeki 13 ilin 2015 yılından 2019 yılına toplam gübre, toplam biyogaz ve toplam enerji miktarının arttığı görülmektedir. 2015 yılında toplam enerji miktarı $3410 \mathrm{GWh}$ ve 2019 yılındaki toplam enerji miktarı ise $4275 \mathrm{GWh}$ olarak hesaplanmıştır. Şekil 4' te ise 2015 yılı ve 2019 yılı için biyogaz üretim potansiyelleri karşılaştırıldığında ise en fazla artışın Konya ilinde en az artışın ise Sivas ilinde olduğu görülmektedir. Biyogazdan faydalanacak kişi sayısı ise 2015 ve 2019 yılları için sırası ile 662657 ve 830773 olarak belirlenmiştir. 2019 yılı iç Anadolu Bölgesi nüfusu 12705812 kişi olarak belirlenmiştir. Biyogazdan faydalanacak kişi sayısı ise 2019 verilerine göre bölgenin toplam nüfusunun \% 6.5' lik kısmına karşılık gelmektedir. Çizelge $6^{\prime}$ da iç Anadolu Bölgesi'nde 2019 yılı için farklı atık kaynaklarından üretilebilecek biyogaz potansiyeli ile diğer yakıtlar ile karşılaştırıldığında önemli bir potansiyele sahip olduğu görülmektedir. Diğer kaynakların sınırlı olması hayvan atıklarından biyogaz üretimini cazip hale getirmektedir. 
Çizelge 3. İç Anadolu illerine ait büyükbaş, küçükbaş, kanatlı hayvan sayıları ve elde edilecek gübre, biyogaz miktarları (2015)

\begin{tabular}{|c|c|c|c|c|c|c|c|c|c|}
\hline iller & $\begin{array}{l}\text { BBH } \\
\text { sayısı }\end{array}$ & $\begin{array}{l}\text { Gübre miktarı } \\
\text { (ton.yıl }^{-1} \text { ) }\end{array}$ & $\begin{array}{l}\text { Biyogaz miktarı } \\
\left(\mathrm{m}^{3} \cdot \mathrm{yl}^{-1}\right)\end{array}$ & KBH sayısı & $\begin{array}{l}\text { Gübre miktarı } \\
{\text { (ton.yıl }{ }^{-1} \text { ) }}\end{array}$ & $\begin{array}{l}\text { Biyogaz miktarı } \\
\left(\mathrm{m}^{3} \cdot \mathrm{yll}^{-1}\right)\end{array}$ & KH sayısı & $\begin{array}{l}\text { Gübre miktarı } \\
\text { (ton.yıl }^{-1} \text { ) }\end{array}$ & $\begin{array}{l}\text { Biyogaz miktarı } \\
\left(\mathrm{m}^{3} \cdot \mathrm{yll}^{-1}\right)\end{array}$ \\
\hline Aksaray & 181370 & 652932 & 21546756 & 513002 & 359101.4 & 20827881.2 & 315121 & 6932.662 & 540747.64 \\
\hline Ankara & 340112 & 1224403.2 & 40405305.6 & 1062522 & 743765.4 & 43138393.2 & 15164533 & 333619.726 & 26022339 \\
\hline Çankırı & 128376 & 462153.6 & 15251068.8 & 122265 & 85585.5 & 4963959 & 3033324 & 66733.128 & 5205184 \\
\hline Eskişehir & 128466 & 462477.6 & 15261760.8 & 808392 & 565874.4 & 32820715.2 & 4333923 & 95346.306 & 7437011.9 \\
\hline Karaman & 59206 & 213141.6 & 7033672.8 & 616976 & 431883.2 & 25049225.6 & 1138660 & 25050.52 & 1953940.6 \\
\hline Kayseri & 293074 & 1055066.4 & 34817191.2 & 638542 & 446979.4 & 25924805.2 & 3745266 & 82395.852 & 6426876.5 \\
\hline Kırıkkale & 62423 & 224722.8 & 7415852.4 & 116258 & 81380.6 & 4720074.8 & 670607 & 14753.354 & 1150761.6 \\
\hline Kırşehir & 141614 & 509810.4 & 16823743.2 & 218897 & 153227.9 & 8887218.2 & 773658 & 17020.476 & 1327597.1 \\
\hline Konya & 740148 & 2664532.8 & 87929582.4 & 2117190 & 1482033 & 85957914 & 12387101 & 272516.222 & 21256265 \\
\hline Nevşehir & 74103 & 266770.8 & 8803436.4 & 120212 & 84148.4 & 4880607.2 & 825779 & 18167.138 & 1417036.8 \\
\hline Niğde & 147879 & 532364.4 & 17568025.2 & 546768 & 382737.6 & 22198780.8 & 883299 & 19432.578 & 1515741.1 \\
\hline Sivas & 265355 & 955278 & 31524174 & 468960 & 328272 & 19039776 & 688161 & 15139.542 & 1180884.3 \\
\hline Yozgat & 244350 & 879660 & 29028780 & 407867 & 285506.9 & 16559400.2 & 1047705 & 23049.51 & 1797861.8 \\
\hline TOPLAM & 2806476 & 10103313.6 & 333409348.8 & 7757851 & 5430495.7 & 314968750.6 & 45007137 & 990157.014 & 77232247 \\
\hline
\end{tabular}

Çizelge 4. İç Anadolu illerine ait büyükbaş, küçükbaş, kanatlı hayvan sayıları ve elde edilecek gübre, biyogaz miktarları (2019).

\begin{tabular}{|c|c|c|c|c|c|c|c|c|c|}
\hline iller & BBH sayısı & $\begin{array}{l}\text { Gübre miktarı } \\
\text { (ton.yıl }^{-1} \text { ) }\end{array}$ & $\begin{array}{l}\text { Biyogaz miktarı } \\
\left(\mathrm{m}^{3} \cdot \mathrm{yll}^{-1}\right)\end{array}$ & KBH sayısı & $\begin{array}{l}\text { Gübre miktarı } \\
\text { (ton.yıl }^{-1} \text { ) }\end{array}$ & $\begin{array}{l}\text { Biyogaz miktarı } \\
\left(\mathrm{m}^{3} \cdot \mathrm{yll}^{-1}\right)\end{array}$ & KH sayısı & $\begin{array}{l}\text { Gübre miktarı } \\
\text { (ton.yıl }^{-1} \text { ) }\end{array}$ & $\begin{array}{l}\text { Biyogaz miktarı } \\
\left(\mathrm{m}^{3} \cdot \mathrm{yll}^{-1}\right)\end{array}$ \\
\hline Aksaray & 310549 & 1117976.4 & 36893221.2 & 753765 & 527635.5 & 30602859 & 319057 & 7019.254 & 547501.812 \\
\hline Ankara & 549774 & 1979186.4 & 65313151.2 & 1746476 & 1222533.2 & 70906925.6 & 11443686 & 251761.092 & 19637365.18 \\
\hline Çankırı & 154860 & 557496 & 18397368 & 135983 & 95188.1 & 5520909.8 & 2961354 & 65149.788 & 5081683.464 \\
\hline Eskişehir & 162855 & 586278 & 19347174 & 1034359 & 724051.3 & 41994975.4 & 4286068 & 94293.496 & 7354892.688 \\
\hline Karaman & 71134 & 256082.4 & 8450719.2 & 676377 & 473463.9 & 27460906.2 & 1120620 & 24653.64 & 1922983.92 \\
\hline Kayseri & 350237 & 1260853.2 & 41608155.6 & 651505 & 456053.5 & 26451103 & 4374950 & 96248.9 & 7507414.2 \\
\hline Kirıkkale & 77775 & 279990 & 9239670 & 145244 & 101670.8 & 5896906.4 & 306037 & 6732.814 & 525159.492 \\
\hline Kurşehir & 236901 & 852843.6 & 28143838.8 & 286682 & 200677.4 & 11639289.2 & 887187 & 19518.114 & 1522412.892 \\
\hline Konya & 927082 & 3337495.2 & 110137341.6 & 2459960 & 1721972 & 99874376 & 13218994 & 290817.868 & 22683793.7 \\
\hline Nevşehir & 109635 & 394686 & 13024638 & 179081 & 125356.7 & 7270688.6 & 985067 & 21671.474 & 1690374.972 \\
\hline Niğgde & 172019 & 619268.4 & 20435857.2 & 589828 & 412879.6 & 23947016.8 & 894638 & 19682.036 & 1535198.808 \\
\hline Sivas & 385612 & 1388203.2 & 45810705.6 & 636582 & 445607.4 & 25845229.2 & 772154 & 16987.388 & 1325016.264 \\
\hline Yozgat & 245825 & 884970 & 29204010 & 340094 & 238065.8 & 13807816.4 & 663320 & 14593.04 & 1138257.12 \\
\hline TOPLAM & 3754258 & 13515328.8 & 446005850.4 & 9635936 & 6745155.2 & 391219001.6 & 42233132 & 929128.904 & 72472054.51 \\
\hline
\end{tabular}


Türk Tarım ve Doğa Bilimleri Dergisi 8(4): 905-912, 2021

Çizelge 5. İ̧̧ Anadolu illerine ait büyükbaş, küçükbaş ve kanatılı hayvan atıklarından elde edilecek gübre, biyogaz, enerji potansiyeli ve faydalanacak kişi sayısı.

\begin{tabular}{|c|c|c|c|c|c|c|c|c|}
\hline \multirow[t]{2}{*}{ iller } & \multicolumn{2}{|c|}{ Toplam Gübre (ton.yıl ${ }^{-1}$ ) } & \multicolumn{2}{|c|}{ Toplam Biyogaz $\left(\mathrm{m}^{3} \cdot \mathrm{yl}^{-1}\right)$} & \multicolumn{2}{|c|}{ Toplam Enerji (kWh) } & \multicolumn{2}{|c|}{ Faydalanacak Kişi Sayısı } \\
\hline & 2015 & 2019 & 2015 & 2019 & 2015 & 2019 & 2015 & 2019 \\
\hline Aksaray & 1123698.306 & 1404622.796 & 55519487.87 & 68697042.09 & 260941593 & 322876097.8 & 50702.73 & 62737.02474 \\
\hline Ankara & 2301788.326 & 3453480.692 & 109566037.4 & 155857442 & 514960375.9 & 732529977.3 & 100060.3 & 142335.5634 \\
\hline Çankırı & 4419082.022 & 5350285.068 & 195143761.7 & 232695511.3 & 917175680.1 & 1093668903 & 178213.5 & 212507.3163 \\
\hline Eskişehir & 670075.32 & 754199.94 & 34036838.96 & 37834609.32 & 159973143.1 & 177822663.8 & 31083.87 & 34552.15463 \\
\hline Karaman & 320856.754 & 388393.614 & 13286688.81 & 15661735.89 & 62447437.42 & 73610158.69 & 12133.96 & 14302.95515 \\
\hline Kayseri & 1018966.062 & 1652631.154 & 42915384.84 & 68043582.01 & 201702308.7 & 319804835.5 & 39192.13 & 62140.25755 \\
\hline Kırıkkale & 934534.578 & 1051830.036 & 41282547.08 & 45918072.81 & 194027971.3 & 215814942.2 & 37700.96 & 41934.31307 \\
\hline Kırşehir & 369086.338 & 541714.174 & 15101080.36 & 21985701.57 & 70975077.71 & 103332797.4 & 13790.94 & 20078.26628 \\
\hline Konya & 680058.776 & 1073039.114 & 27038558.53 & 41305540.89 & 127081225.1 & 194136042.2 & 24692.75 & 37721.95515 \\
\hline Nevşehir & 1584441.652 & 1813155.6 & 67168872.86 & 75566672.8 & 315693702.4 & 355163362.2 & 61341.44 & 69010.66009 \\
\hline Niğde & 1298689.542 & 1850797.988 & 51744834.28 & 72980951.06 & 243200721.1 & 343010470 & 47255.56 & 66649.27038 \\
\hline Sivas & 1188216.41 & 1137628.84 & 47386041.98 & 44150083.52 & 222714397.3 & 207505392.5 & 43274.92 & 40319.71098 \\
\hline Yozgat & 614472.228 & 717833.888 & 25420211.78 & 28999961.26 & 119474995.4 & 136299817.9 & 23214.81 & 26483.98289 \\
\hline TOPLAM & 16523966.31 & 21189612.9 & 725610346.5 & 909696906.5 & 3410368629 & 4275575461 & 662657.9 & 830773.4306 \\
\hline
\end{tabular}




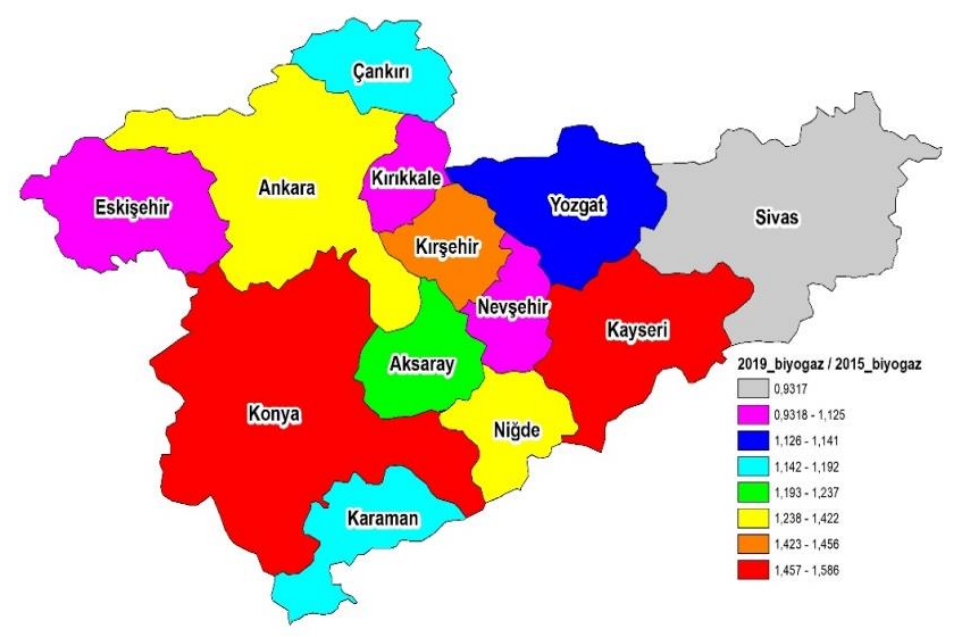

Şekil 4. 2015-2019 yılları biyogaz potansiyeli artış oranı

Çizelge 6. İç Anadolu Bölgesi farklı atık kaynaklarından üretilebilecek biyogazın farklı yakıtlarda denkliği

\begin{tabular}{|c|c|c|c|c|}
\hline & Biyogaz $\left(\mathrm{m}^{3}\right)$ & Odun $(\mathrm{kg})$ & Benzin (I) & Motorin (I) \\
\hline Büyükbaş & 446005850.4 & 1547640300.9 & 356804680.3 & 294363861.2 \\
\hline Küçükbaş & 391219001.6 & 1357529933.5 & 312975201.2 & 258204541.0 \\
\hline Kanatlı & 72472054.5 & 251478029.1 & 57977643.6 & 47831555.9 \\
\hline TOPLAM & $\mathbf{9 1 2 6 9 6 9 0 6 . 5}$ & $\mathbf{3 1 5 6 6 4 8 2 6 3 . 5}$ & $\mathbf{7 2 7 7 5 7 5 2 5 . 2}$ & $\mathbf{6 0 0 3 9 9 9 5 8 . 1}$ \\
\hline
\end{tabular}

\section{Sonuç ve Öneriler}

Kömür, petrol ve doğalgaz gibi fosil yakıt kaynaklarının gün geçtikçe azalmasından dolayı güneş, rüzgar, jeotermal ve biyokütle kaynaklı yenilenebilir ve temiz enerjiye olan ihtiyaç artmıştır. Biyogaz üretiminden kullanılan organik atıklar biyogaz üretiminde kullanılırken ortaya çıkan atıklarda tarımda kullanılmak üzere organik gübre olarak değerlendirilmektedir. Bu çalışmada iç Anadolu Bölgesi' nin biyogaz potansiyeli incelenmiş ve yıllara göre değişimi değerlendirilmiştir. İç Anadolu Bölgesi içerisinde bulunan bütün illeri $\mathrm{BBH}, \mathrm{KBH}$ ve $\mathrm{KH}$ sayıları yıllara göre belirlenmiş, biyogaz ve enerji miktarları hesaplanmıştır. 2015 yılında toplam enerji miktarı 3410 GWh ve 2019 yılındaki toplam enerji miktarı ise $4275 \mathrm{GWh}$ olarak hesaplanmıştır. Biyogazdan nüfus artış hızı incelendiğinde 2015 yılından 2019 yılına \% 5.88' lik bir nüfus artışı gözlenmiştir. Biyogazdan faydalanacak kişi sayısı ile

2015 yılından 2019 yılına \% 25.36 artış göstermiştir.

Toplam nüfusta artış olmasına rağmen faydalanacak kişi sayısında düşme olmamıştır. Bu da artan nüfus ile birlikte artan hayvan sayısı ve atıklardan elde edilen biyogaz miktarı ile ilişkilendirilebilir. Biyogaz üretim tesislerinin yapılması temiz ve yenilenebilir enerji elde edilmesi dışında ayrıca istihdam sağlanması ekonomik açıdan da fayda sağlayacaktır. Tesis için gerekli olan atıkların kaynağını büyük oranda hayvan çiftlikleri sağlasa da barınak, hayvan hastanesi gibi kuruluşların atıkları da bu tesislerde bertaraf edilerek çevre kirliliğine neden olmaları engellenebilir. Biyogaz üretimi sonrasında oluşan atıklar ise uygulanan işlemler sonrasında rahatsız edici kokusunu kaybederek gübre olarak tarım alanında kullanılabilir. Bu sayede ticari gübre kullanımı azaltılarak maliyet düşürülmüş olur.

Çıkar Çatışması Beyanı: Makale yazarları aralarında herhangi bir çıkar çatışması olmadı̆̆ını beyan ederler.

Araştırmacıların Katkı Oranı Beyan Özeti: Yazarlar makaleye eşit oranda katkı sağlamış olduklarını beyan ederler.

\section{Kaynaklar}

Altıkat, S., and Çelik, A., 2012. Iğdır ilinin hayvansal atık kaynaklı biyogaz potansiyeli biogas potential from animal waste of ığdır province. Iğdır Üniversitesi Fen Bilimleri Enstitüsü Dergisi, 2 (1): 61-66.

Baran, M. F., Lüle, F., and Gökdoğan, O., 2017. 
Adıyaman ilinin hayvansal atıklardan elde edilebilecek enerji potansiyeli. Türk Tarım ve Doğa Bilimleri Dergisi, 4 (3): 245-249.

Bulut, A. P., and Canbaz, G. T., 2019. Hayvan atıklarından Sivas ili biyogaz potansiyelinin araştırılması. Karaelmas Fen ve Mühendislik Dergisi, 9 (1): 1-10.

Çağlayan, G. H. 2020. Doğu anadolu bölgesindeki büyükbaş ve küçükbaş hayvan atıklarının biyogaz potansiyelinin incelenmesi. Türk Tarım ve Doğa Bilimleri Dergisi, , 7 (3): 672681.

Çağlayan, G. H., and Koçer, N. N., 2014. Evaluatıon of the potential of livestock breedıng in the cıty of muş for the research of bıgas productıon. Muş Alparslan Üniversitesi Fen Bilimleri Dergisi, 2 (1): 215-220.

Deviren, H., Illkiliç, C., and Aydin, S., 2017. Biyogaz Üretiminde Kullanılabilen Materyaller ve Biyogazın Kullanım Alanları. Batman Üniversitesi Yaşam Bilimleri Dergisi, 7 (2): 79-89.

Hammad, M., Badarneh, D., and Tahboub, K., 1999. Evaluating variable organic waste to produce methane. Energy Conversion \& Management, 40 (13): 1463-1475.

Kadam, R., and Panwar, N. L., 2017. Recent advancement in biogas enrichment and its applications Recent advancement in biogas enrichment and its applications. Renewable and Sustainable Energy Reviews, 73: 892903.

Karim, K., Hoffmann, R., Klasson, K. T., and Aldahhan, M. H., 2005. Anaerobic digestion of animal waste: Effect of mode of mixing. Water Research , 39 (15): 3597-3606.

Koçer, N. N., and Kurt, G., 2013. Malatya' da hayvancılık potansiyeli ve biyogaz üretimi. Sakarya Üniversitesi Fen Bilimleri Enstitüsü Dergisi, 17 (1): 1-8.

TÜik, Haycancılık İstatistikleri, https://biruni.tuik.gov.tr/bolgeselistatistik/ta bloOlustur.do (15.10.2020)

Yasar, A., Nazir, S., Rasheed, R., Tabinda, A. B., and Nazar, M., 2017. Economic review of di ff erent designs of biogas plants at household level in Pakistan. Renewable and Sustainable Energy Reviews, 74: 221-229. 